\title{
Dosing of Biologics in Juvenile Idiopathic Arthritis: Is the Sky the Limit?
}
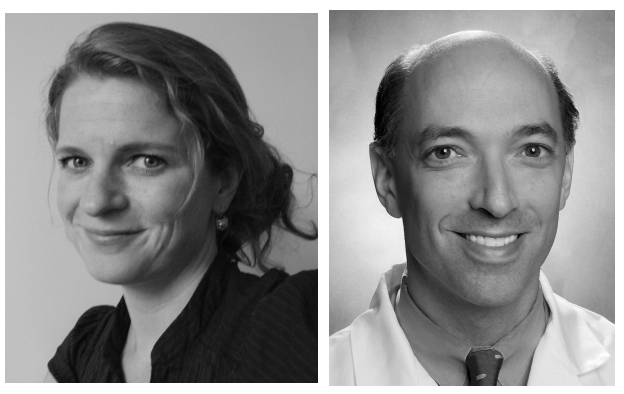

In the past decade, biologic therapy has been a valuable new option in the treatment of both adult and pediatric rheumatic diseases. Many patients previously refractory to antirheumatic drugs have shown excellent responses to biologic therapy. However, there remains a significant minority of patients who do not respond to these drugs or who lose efficacy after a period of successful treatment. Why are some patients with inflammatory arthritis primary or secondary nonresponders? Part of the problem is likely due to the heterogeneous nature of the disease. But insufficient dosing might be an issue for some patients.

In drug research, dosing is evaluated by pharmacodynamic and pharmacokinetic (PK) models and then tested in humans for a safe dosage range and possible side effects before a drug is tested for its efficacy ${ }^{1,2}$. Unfortunately, a large proportion of medicines (50-90\%) used in children are prescribed outside the terms of the drug license, i.e., off-label, which can place children at a direct risk of under- or overdosing and a delayed risk of longterm adverse effects ${ }^{3}$. The US Food and Drug Administration (FDA) has provided an incentive to US pharmaceutical companies since 1997 to study products that could be beneficial for the pediatric population ${ }^{3,4}$. The European Union (EU) enforced the Paediatric Regulation in $2007^{5}$. The goals of the EU legislation are similar to those of US pediatric legislation: to improve children's health through advancements in research and to provide a new framework for evaluating the efficacy and safety of medicines for children $^{3,6}$. However, in the EU, it is mandatory to send a pediatric investigation or development plan as early as the end of PK studies in adults for all new medicinal products in development unless a waiver is granted ${ }^{5}$. The US and EU regulations were developed to stimulate more pediatric drug research and development of pediatric medicines. As a result, many clinical studies have been conducted to evaluate the clinical pharmacology, efficacy, and safety in pediatric patients, determine proper dosing, identify the risks and benefits of therapies, and improve drug labeling for pediatric patients ${ }^{1}$.
The role of clinical pharmacology includes comparing exposure between adult and pediatric patients, bridging different formulations and regimens, providing appropriate dose selection recommendations with a modeling and simulation approach, and helping design more efficient studies ${ }^{1}$. In pediatric rheumatology, the dose selection in the trial design mostly uses the prior PK and dosing regimen information from adult patients with rheumatoid arthritis (RA) ${ }^{1}$. This poses 2 issues: (1) how to account for the confounding effect of developmental growth and variability in individual response regarding the evaluation of pharmacogenetics and pharmacogenomics factors in children ${ }^{7}$; and (2) that doses in trials are tested for the average patient aiming for effect with the least toxicity. However, in routine practice, patients differ in many ways, including genetics, age, sex, weight, metabolism, liver function, comorbidity, and co-medication ${ }^{8}$.

In the case of biologic agents in the treatment of JIA, dosages based on trial data have been established. Clinical trials evaluate drug dosages that have an acceptable level of toxicity and are efficacious. However, this might not always produce the desired results for all patients. In clinical practice, physicians sometimes raise the dose when the drug effect is insufficient. Little is known about effectiveness and safety of high doses of biologics in JIA. The current American College of Rheumatology guidelines for the initiation and safe monitoring of drug treatments in JIA do not mention changing $\operatorname{dose}^{9}$ but recommend switching biologic therapies if there is inadequate response after 4 months of treatment.

In this issue of The Journal, Tambralli, et al present the results of a retrospective study of 58 children with JIA who received "high dose" infliximab (range $10-24 \mathrm{mg} / \mathrm{kg} / \mathrm{dose})^{10}$. Infliximab is approved for use in Crohn disease, RA, ankylosing spondylitis, psoriasis, psoriatic arthritis, and ulcerative colitis ${ }^{11}$. However, unlike 2 other anti-tumor necrosis factor biologic agents, etanercept and adalimumab, infliximab is not approved for JIA. In a randomized, double-blind, placebo-controlled trial performed from 2001

See High doses of infliximab in the management of JIA, page 1749

Personal non-commercial use only. The Journal of Rheumatology Copyright $\odot$ 2013. All rights reserved. 
to 2004 , efficacy of infliximab was not proven $^{12}$. In that trial, 122 patients with JIA (4-17 yrs) were randomized to receive infliximab $3 \mathrm{mg} / \mathrm{kg}$ plus methotrexate (MTX) through Week 44 (infliximab group) or MTX plus placebo for 14 weeks followed by MTX plus infliximab $6 \mathrm{mg} / \mathrm{kg}$ through Week 44 (placebo group) ${ }^{1,12}$. Remarkably, safety data indicated that the $6 \mathrm{mg} / \mathrm{kg}$ dose may provide a more favorable risk/benefit profile compared to the $3 \mathrm{mg} / \mathrm{kg}$ dose, although overall infliximab was well tolerated. The detection of antibodies against infliximab was significantly associated with the occurrence of infusion reactions in the group using $3 \mathrm{mg} / \mathrm{kg}$. The trial failure was attributed to factors such as greater placebo effect and lower PK exposure. According to retrospective case collections and open case series, the efficacy of infliximab on articular symptoms seems to be comparable to that of etanercept in the treatment of JIA ${ }^{13}$. However, for treatment of chronic JIA-associated uveitis and inflammatory bowel disease (IBD), infliximab seems to be superior to etanercept $\mathrm{t}^{13,14,15}$. Incompatibility reactions during infusions are not rare and are probably related to the development of human antichimeric antibodies; therefore, infliximab should be used only in combination with MTX to prevent the development of such antichimeric antibodies ${ }^{13}$. Dosages of 3 to 6 $\mathrm{mg} / \mathrm{kg}$ body weight and infusion intervals of 4 to 8 weeks have been studied, but higher dosages up to $10 \mathrm{mg} / \mathrm{kg}$ and shorter intervals are preferred ${ }^{13,14}$.

Tambralli and colleagues recognized that studies of children with uveitis and adults with IBD have shown that dose intensification can lead to improved responses ${ }^{16,17,18,19,20}$. Doses of infliximab as high as $10-20 \mathrm{mg} / \mathrm{kg}$ have been reported to be effective in the management of childhood uveitis, and the FDA label for RA permits doses as high as $10 \mathrm{mg} / \mathrm{kg}$ every 4 weeks. Therefore they evaluated patients with refractory JIA who received at least 1 dose of high-dose infliximab ( $\geq 10 \mathrm{mg} / \mathrm{kg}$ ) at any time between January 1, 2006, and June 30, 2012, in a single hospital. Data were collected from routine visits including serious adverse events, medically important infections, and disease activity measures, and examined for the first year following initiation of high-dose infliximab. The authors conclude that high-dose infliximab is safe in the management of JIA. The safety of biologicals, especially in a vulnerable patient group such as children, has been of general concern. The fact that the authors have not identified any new short-term safety concerns in their study is encouraging.

This study is an important contribution to the existing literature, because data on high doses of biologics in the treatment of JIA are rare. The goal of optimizing a drug's dosage is to find the right therapeutic window: high enough for the optimal treatment effect but not high enough to cause adverse effects. Because of between-patient variations in drug metabolism, the optimal dose will be different for every patient. Identifying the clinical, biological, and/or genetic markers that allow tailored dosing is a challenge. It might improve treatment not only for pediatric patients but also for adults.

New legislation concerning drug research in children has encouraged pharmaceutical companies in the United States and the EU to perform pediatric drug research. The data guiding the dosing, efficacy, and safety of medicines for children have lagged substantially compared to the information available for adults ${ }^{21}$. There is a lack of knowledge of optimal dosing of biologic agents in JIA; some patients might benefit from higher doses. Although safety issues are a big concern, underdosing and therefore not providing an optimal treatment also harms the patient. We need more research to find the right therapeutic window for each patient, making sure that they are treated effectively but not overdosed, causing avoidable side effects or producing unnecessary drug costs.

\section{FEMKE H.M. PRINCE, MD, PhD, MSCE,}

Department of Paediatrics, Academic Medical Centre, Emma Children's Hospital, Amsterdam, Netherlands;

DANIEL H. SOLOMON, MD, MPH,

Divisions of Rheumatology, Immunology and Allergy and Pharmacoepidemiology, Brigham and Women's Hospital, Harvard Medical School,

Boston, Massachusetts, USA

Address correspondence to Dr. F.H.M. Prince, Academic Medical Centre, Emma Children's Hospital, Department of Pediatrics, H7-270, Meibergdreet 9, Amsterdam, 1105 A2, the Netherlands.

E-mail: femkeprince@gmail.com

\section{REFERENCES}

1. Ji P, Chowdhury BA, Yim S, Sahajwalla CG. Dosing regimen determination for juvenile idiopathic arthritis: a review of studies during drug development. J Pharm Sci 2012;101:2621-34.

2. De Cock RF, Piana C, Krekels EH, Danhof M, Allegaert K, Knibbe CA. The role of population PK-PD modelling in paediatric clinical research. Eur J Clin Pharmacol 2011;67 Suppl 1:5-16.

3. Auby P. Pharmaceutical research in paediatric populations and the new EU paediatric legislation: an industry perspective. Child Adolesc Psychiatry Ment Health 2008;2:38.

4. US Food and Drug Administration (FDA). US Food and Drug Administration Modernization Act. 1997. [Internet. Accessed July 23 , 2013.] Available from: www.gpo.gov/fdsys/pkg/USCODE-2010-title21/ pdf/USCODE-2010-title21-chap9-subchapV-partA-sec355a.pdf

5. European Medicines Agency (EMA). The European paediatric initiative: history of the paediatric regulation. 2007. [Internet. Accessed July 23, 2013.] Available from: www.ema.europa.eu/docs/en_GB/document_library/Other/2009/09/ WC500003693.pdf

6. Edginton AN. Knowledge-driven approaches for the guidance of first-in-children dosing. Paediatr Anaesth 2011;21:206-13.

7. Piana C, Surh L, Furst-Recktenwald S, Iolascon A, Jacqz-Aigrain EM, Jonker I, et al. Integration of pharmacogenetics and pharmacogenomics in drug development: implications for regulatory and medical decision making in pediatric diseases. J Clin Pharmacol 2012;52:704-16.

8. Kearns GL, Abdel-Rahman SM, Alander SW, Blowey DL, Leeder JS, Kauffman RE. Developmental pharmacology - drug disposition,

Personal non-commercial use only. The Journal of Rheumatology Copyright (c) 2013. All rights reserved. 
action, and therapy in infants and children. $\mathrm{N}$ Engl $\mathrm{J}$ Med 2003;349:1157-67.

9. Beukelman T, Patkar NM, Saag KG, Tolleson-Rinehart S, Cron RQ, DeWitt EM, et al. 2011 American College of Rheumatology recommendations for the treatment of juvenile idiopathic arthritis: initiation and safety monitoring of therapeutic agents for the treatment of arthritis and systemic features. Arthritis Care Res 2011;63:465-82.

10. Tambralli A, Beukelman T, Weiser P, Atkinson TP, Cron RQ, Stoll ML. High doses of infliximab in the management of juvenile idiopathic arthritis. J Rheumatol 2013;40:1749.

11. de Vries HS, van Oijen MG, Driessen RJ, de Jong EM, Creemers $\mathrm{MC}$, Kievit W, et al. Appropriate infliximab infusion dosage and monitoring: results of a panel meeting of rheumatologists, dermatologists and gastroenterologists. Br J Clin Pharmacol 2011;71:7-19.

12. Ruperto N, Lovell DJ, Cuttica R, Wilkinson N, Woo P, Espada G, et al. A randomized, placebo-controlled trial of infliximab plus methotrexate for the treatment of polyarticular-course juvenile rheumatoid arthritis. Arthritis Rheum 2007;56:3096-106.

13. Horneff G. Update on biologicals for treatment of juvenile idiopathic arthritis. Expert Opin Biol Ther 2013;13:361-76.

14. Prince FH, Otten MH, van Suijlekom-Smit LW. Diagnosis and management of juvenile idiopathic arthritis. BMJ 2010;341:c6434.

15. Yang LS, Alex G, Catto-Smith AG. The use of biologic agents in pediatric inflammatory bowel disease. Curr Opin Pediatr 2012;24:609-14.
16. Sukumaran S, Marzan K, Shaham B, Reiff A. High dose infliximab in the treatment of refractory uveitis: does dose matter? ISRN Rheumatol 2012;2012:765380.

17. Regueiro M, Siemanowski B, Kip KE, Plevy S. Infliximab dose intensification in Crohn's disease. Inflamm Bowel Dis 2007;13:1093-9.

18. Katz L, Gisbert JP, Manoogian B, Lin K, Steenholdt C, Mantzaris GJ, et al. Doubling the infliximab dose versus halving the infusion intervals in Crohn's disease patients with loss of response. Inflamm Bowel Dis 2012;18:2026-33.

19. Kopylov U, Mantzaris GJ, Katsanos KH, Reenaers C, Ellul P, Rahier JF, et al. The efficacy of shortening the dosing interval to once every six weeks in Crohn's patients losing response to maintenance dose of infliximab. Aliment Pharmacol Ther 2011;33:349-57.

20. Kahn P, Weiss M, Imundo LF, Levy DM. Favorable response to high-dose infliximab for refractory childhood uveitis. Ophthalmology 2006;113:860-4 e2.

21. Rakhmanina NY, van den Anker JN. Pharmacological research in pediatrics: from neonates to adolescents. Adv Drug Deliv Rev 2006;58:4-14

J Rheumatol 2013;40:1643-5; doi:10.3899/jrheum.130875 